\title{
Immunocytochemical Localization of the Postsynaptic Density Protein PSD-95 in the Mammalian Retina
}

\author{
Peter Koulen, ${ }^{1}$ Erica L. Fletcher, ${ }^{1}$ Sarah E. Craven, ${ }^{2}$ David S. Bredt, ${ }^{2}$ and Heinz Wässle ${ }^{1}$ \\ ${ }^{1}$ Max-Planck-Institut für Hirnforschung, D-60528 Frankfurt, Germany, and '2Department of Physiology, University of \\ California at San Francisco, San Francisco, California 94143
}

\begin{abstract}
Synapse-associated proteins are the scaffold for the selective aggregation of ion channels at synapses; they provide the link to cytoskeletal elements and possibly are involved with the regulation of synaptic efficacy by electrical activity. The localization of the postsynaptic density protein PSD-95 was studied in different mammalian retinae (rat, monkey, and tree shrew) by using immunocytochemical methods. Immunofluorescence for PSD-95 was most prominent in the outer plexiform layer (OPL). The axon terminals of rods and cones, the rod spherules and cone pedicles, were strongly labeled. Electron microscopy, using preembedding immunocytochemistry, showed PSD-95 localized presynaptically within the photoreceptor terminals. Distinct PSD-95 labeling was also present in the inner plexiform layer (IPL). It had a punctate appearance suggesting the synaptic clustering of PSD-95 in the IPL. Electron microscopy showed that PSD-95 was concentrated in processes that were
\end{abstract}

postsynaptic at bipolar cell ribbon synapses (dyads). As a rule, only one of the two postsynaptic members of the dyad was labeled for PSD-95. Double-labeling experiments were performed for PSD-95 and for SAP 102 or PSD-93, respectively, two other members of the family of synapse-associated proteins. All three were found to be colocalized in the synaptic hot spots in the IPL. In the OPL, however, PSD-95 and PSD-93 were found presynaptically, whereas SAP 102 was located postsynaptically at photoreceptor synapses. Double-labeling experiments also were performed for PSD-95 and for the NR1 subunit of the NMDA receptor. They were found to be colocalized in synaptic hot spots in the IPL.

Key words: PSD-95; SAP 102; PSD-93; NMDA receptors; NR1 subunit; postsynaptic density; receptor clustering; cone pedicle; rod spherule
The postsynaptic density (PSD) is a complex network of transmitter receptors, anchoring proteins, and cytoskeletal elements (Kennedy, 1997). The selective concentration of transmitter receptors in PSDs not only is essential for the reliable and rapid synaptic transmission but also plays an important role in synaptic plasticity and possibly in memory formation (Mammen et al., 1997; Rao and Craig, 1997; Kirsch and Betz, 1998).

The postsynaptic density protein PSD-95 belongs to a family of ion channel clustering molecules (for review, see Gomperts, 1996; Sheng, 1996; Kennedy, 1997). In its N-terminal part PSD-95 contains three highly homologous regions of $\sim 90$ amino acids. They have been called PDZ domains because they have been found in postsynaptic density proteins (PSDs), in the Drosophila tumor suppressor gene "disks large" $(D l g)$, and in cell-cell adhesion proteins like zonula occludens-1 (ZO1). In mammals this family of postsynaptic density proteins includes four closely related proteins: PSD-95/SAP 90 (Cho et al., 1992; Kistner et al., 1993), SAP 97/hdlg (Lue et al., 1994; Müller et al., 1995), PSD93/Chapsyn-110 (Brenman et al., 1996a; Kim et al., 1996), and SAP 102 (Müller et al., 1996).

The second PDZ domain in PSD-95 has been shown by the

\footnotetext{
Received July 8, 1998; revised Sept. 8, 1998; accepted Sept. 15, 1998.

This work was supported by Deutsche Forschungsgemeinschaft Grant SFB 269/ B4, National Health and Medical Research Council (Australia), C. J. Martin Fellowship (to E.L.F.), and National Institutes of Health Grant RO1 GM36017. We thank F. Boij, A. Hildebrand, W. Hofer, and G. S. Nam for excellent technical assistance; Dr. C. C. Garner for providing antibodies; and I. Odenthal for typing this manuscript.

Correspondence should be addressed to Dr. Heinz Wässle, Max-Planck-Institut für Hirnforschung, Neuroanatomie, Deutschordenstrasse 46, D-60528 Frankfurt, Germany.

Copyright (C) 1998 Society for Neuroscience $0270-6474 / 98 / 1810136-14 \$ 05.00 / 0$
}

yeast two-hybrid method to bind tightly to the $\mathrm{COOH}$ tail of the NMDA receptor subunit $2(\mathrm{NR} 2)$ and of the Shaker-type $\mathrm{K}^{+}$ channels, respectively (Kim et al., 1995; Kornau et al., 1995; Niethammer et al., 1996). Brenman et al. (1996b) described the PDZ domain of neuronal nitric oxide synthase (nNOS) as binding to the second PDZ domain of PSD-95. An interaction of the third PDZ domain of PSD-95 with the neuronal cell adhesion molecule neuroligin has been found by Irie et al. (1997). These binding studies suggest that PSD-95 is a modular scaffold that aggregates ion channels and links them to several intracellular and transmembrane proteins.

The localization of PSD-95 to various parts of the CNS has been studied with specific antibodies both by light and electron microscopy. Cho et al. (1992) described a punctate immunofluorescence in the hippocampus. Kornau et al. (1995) showed that on the dendrites of cultured hippocampal neurons the puncta are in register with NR2B clusters. Hunt et al. (1996) demonstrated by electron microscopy that PSD-95 in the forebrain was associated with postsynaptic densities. In contrast, a presynaptic localization of PSD-95 was found in the cerebellum (Kistner et al., 1993; Laube et al., 1996).

In the past we have studied the localization of various transmitter receptors in the mammalian retina and found that they are clustered at synaptic sites (for review, see Brandstätter et al., 1998; Wässle et al., 1998). The clusters were highly specific with respect to their subunit composition and the type of synapses at which the subunits were expressed. Therefore, selective sorting mechanisms and protein interactions must be involved. The PDZ domain-containing proteins are primary candidates for targeting transmitter receptors to synapses. 
In a preceding study (Koulen et al., 1998) we have investigated the localization of SAP 102 that, like PSD-95, also has three PDZ domains. It was clustered at postsynaptic sites in the outer plexiform layer (OPL) and inner plexiform layer (IPL), and weak extrasynaptic expression was found in bipolar cells and ganglion cell axons. In the present study we applied specific antibodies against PSD-95 to the rat retina and studied the immunolabeling in the OPL and in the IPL both by light and electron microscopy. To show a possible colocalization of PSD-95 with the closely related synapse-associated proteins PSD-93 and SAP 102, we performed double-labeling experiments. The possible association of PSD-95 and NMDA receptors was studied by double-labeling experiments for PSD-95 and the NR1 subunit of the NMDA receptor.

\section{MATERIALS AND METHODS}

All experiments were performed according to the guidelines for the welfare of experimental animals issued by the Federal Government of Germany.

\section{Antisera}

Two mouse monoclonal antibodies (clone 7E3-1B8 and clone 6G6-1C9; Affinity Bioreagents, Golden, CO) were used to detect PSD-95 immunoreactivity in the rat retina. The specificity of both antibodies was described in Kornau et al. (1995). Because of its specific interaction with PSD-95, clone 7E3-1B8 was chosen for all of the experiments that have been described (diluted 1:200). Although clone 6G6-1C9 was reported to recognize a slightly larger band in addition to a $95 \mathrm{kDa}$ band in Western blots (Kornau et al., 1995), we found identical results in immunocytochemical experiments and no difference in staining specificity when compared with clone 7E3-1B8, as reported previously for other CNS tissues (Kornau et al., 1995). A polyclonal antiserum raised in rabbit against the first 119 amino acids of SAP 102 was used in this study (diluted 1:1500; kindly provided by Dr. C. C. Garner University of Alabama at Birmingham, AL). The antiserum was characterized in detail in Müller et al. (1996). A guinea pig polyclonal antiserum against PSD-93 (diluted 1:2500) was used to visualize the distribution of the protein in the rat retina. The specificity of the antiserum was described in Brenman et al. (1996a,b). Rod bipolar cells were labeled with a polyclonal rabbit antiserum against protein kinase $\mathrm{C} \alpha(\mathrm{PKC} \alpha)$ (Greferath et al., 1990) (diluted 1:10,000; Sigma, Saint Louis, MO). A rabbit polyclonal antiserum directed against a synthetic peptide corresponding to the $\mathrm{C}$ terminus of the NR1 subunit of the NMDA receptor was used to detect the NR1 subunit (diluted 1:25; Chemicon, Temecula, CA).

\section{Tissue preparation}

Retinae of six adult albino rats 6-8 weeks of age, of one adult Macaca mulatta, and of one adult Tupaia belangeri were investigated. Rats were anesthetized deeply with halothane and decapitated. Eyes of $M$. mulatta and of $T$. belangeri were taken from animals that were killed for experiments unrelated to this study by a lethal dose of pentobarbital sodium (Nembutal). After the optic nerve was cut, the superior part of the eye was marked with a felt pen, and the eye was removed. For light microscopy the eyes were opened along the ora serrata, and the eyecups were immersion-fixed for 5,15 , or $30 \mathrm{~min}$ in $4 \%(\mathrm{w} / \mathrm{v})$ paraformaldehyde in phosphate buffer (PB; 0.1 M, pH 7.4). For experiments involving detection of the NR1 subunit, rat retinae were immersion-fixed for 30 and 60 min in 4\% 1-ethyl-3-(3 dimethylaminopropyl) carbodiimide in PB. The vitreous body was removed, and the retinae were dissected free. The marking of the superior part of the retina was conserved by making radial incisions. The retinae were cryoprotected in $10 \%(\mathrm{w} / \mathrm{v})$ and $20 \%(\mathrm{w} / \mathrm{v})$ sucrose in PB for $1 \mathrm{hr}$ each and in $30 \%(\mathrm{w} / \mathrm{v})$ sucrose in PB overnight at $4^{\circ} \mathrm{C}$. Pieces of retinae were frozen in freezing medium (Reichert-Jung, Bensheim, Germany), sectioned vertically at $12 \mu \mathrm{m}$ thickness on a cryostat, and collected on gelatin-coated slides.

For electron microscopy the eyecups were fixed in $4 \%$ (w/v) paraformaldehyde and $0.05 \%$ (v/v) glutaraldehyde in PB for $10 \mathrm{~min}$, followed by an additional $40 \mathrm{~min}$ in $4 \%(\mathrm{w} / \mathrm{v})$ paraformaldehyde in PB. After the retina was dissected out and cryoprotected in 10, 20, and $30 \%(\mathrm{w} / \mathrm{v})$ sucrose, the tissue was frozen and thawed repeatedly to enhance the penetration of the antibodies. After the retina was washed in PBS (0.01
$\mathrm{M}, \mathrm{pH}$ 7.4), small pieces of retina were embedded in agar, and vertical sections $(60 \mu \mathrm{m}$ thick) were cut with a vibratome for preembedding electron microscopic immunocytochemistry.

Depending on the fixation time, differences in the appearance of PSD-95, PSD-93, SAP 102, and especially of NR1 were found. With short and mild fixation (5-10 $\mathrm{min}$ ), immunofluorescence in the IPL had a bright punctate appearance suggesting that single synapses were stained. Unfortunately, such short fixation times resulted in very soft retinal tissue, and in the cryostat sections the tissue often appeared to be ruptured (see Figs. 6, 8, 9, 10). With longer fixation times the quality of the sections was better, but the punctate labeling was much less intense. We exclude that fixation causes a redistribution of synapse-associated proteins. We assume that cross-linking the densely packed synapseassociated proteins by the fixative reduces the accessibility of relevant epitopes. We have found such fixation sensitivity in the past for glycine receptors, $\mathrm{GABA}_{\mathrm{A}}, \mathrm{GABA}_{\mathrm{B}}$, and $\mathrm{GABA}_{\mathrm{C}}$ receptors, and ionotropic and metabotropic glutamate receptors, all of which had a punctate distribution in the IPL (for review, see Brandstätter et al., 1998; Wässle et al., 1998).

\section{Immunocytochemistry}

Light microscopic immunocytochemistry. A specific mouse monoclonal antibody against PSD-95 (clone 7E3-1B8; diluted 1:200) was used in this study. In double-labeling experiments, antibodies known to stain distinct populations of retinal neurons or specific proteins [primary antibodies (pAbs) from rabbit against PKC $\alpha$, SAP 102, and NR1, respectively, and pAbs from guinea pig against PSD-93], were coapplied with the antibody against PSD-95 to characterize its cellular distribution.

Immunocytochemical labeling was performed via the indirect fluorescence method (for details, see Grünert and Wässle, 1993; SassoèPognetto et al., 1994). After being blocked in PBS containing 10\% normal goat serum (NGS), $1 \%$ bovine serum albumin, and $0.05 \%$ Triton $\mathrm{X}-100$, the binding sites of the primary antibodies were revealed by fluorescently labeled secondary antibodies: goat anti-mouse IgG, goat anti-guinea pig IgG, or goat anti-rabbit IgG conjugated to Alexa 564, Alexa 594 (red fluorescence), or Alexa 488 (green fluorescence) (Molecular Probes, Eugene, OR) diluted in PBS containing 3\% NGS, 1\% bovine serum albumin, and $0.05 \%$ Triton $\mathrm{X}-100$.

In double-labeling experiments the sections were incubated in a mixture of the primary antibodies, followed by a mixture of secondary antibodies. To check for antibody specificity, we prepared controls by omitting one of the two primary antibodies during the incubation. In this case only the immunoreactivity for the remaining primary antibody and unspecific background staining were detected, as in the case of single labeling experiments, in which the primary antibody was omitted.

Electron microscopic immunocytochemistry. The vibratome sections were collected in cold PBS, immersed for blocking for $2 \mathrm{hr}$ in $10 \%$ NGS $(\mathrm{v} / \mathrm{v})$ in PBS, and then incubated in the primary antibody against PSD-95. The antibody was diluted 1:200 in the same medium as that used for light microscopy, but without Triton X-100, for $4 \mathrm{~d}$ at $4^{\circ} \mathrm{C}$. Thereafter, the sections were rinsed in PBS several times, and immunolabeling was detected with a biotinylated goat anti-mouse IgG (diluted at 1:100; Vector Laboratories, Burlingame, CA) and a peroxidase-based enzymatic detection system (Vectastain Elite ABC kit, Vector Laboratories). After washes in PBS and in $0.05 \mathrm{M}$ Tris- $\mathrm{HCl}, \mathrm{pH} 7.6$, the sections were preincubated for $10 \mathrm{~min}$ in $3,3^{\prime}$-diaminobenzidine [DAB; $0.05 \%(\mathrm{v} / \mathrm{v})$ in $0.05 \mathrm{M}$ Tris- $\mathrm{HCl}, \mathrm{pH} 7.6]$ and then reacted in $0.05 \%(\mathrm{v} / \mathrm{v}) \mathrm{DAB}$ with $0.01 \%(\mathrm{v} / \mathrm{v}) \mathrm{H}_{2} \mathrm{O}_{2}$. The staining reaction was stopped by rinsing the sections in Tris-HCl. Subsequently, the sections were rinsed in $0.1 \mathrm{M}$ cacodylate buffer, $\mathrm{pH} 7.4$, post-fixed in $2.5 \%(\mathrm{v} / \mathrm{v})$ glutaraldehyde in cacodylate buffer $\left(2 \mathrm{hr}\right.$ at $\left.4^{\circ} \mathrm{C}\right)$, and washed in cacodylate buffer overnight at $4^{\circ} \mathrm{C}$. After several washes in distilled water the $\mathrm{DAB}$ reaction product was silver-intensified by incubation for $10 \mathrm{~min}$ at $60^{\circ} \mathrm{C}$ in a solution containing $2.6 \%$ hexamethylene tetramine, $0.2 \% \mathrm{AgNO}_{3}$, and $0.2 \%$ borax. Then the thoroughly washed sections were treated with a $0.05 \%$ $\mathrm{HAuCl}_{4}$ solution for $3 \mathrm{~min}$ at room temperature and, after further washings in distilled water, were incubated for $3 \mathrm{~min}$ at room temperature in a $2.5 \% \mathrm{Na}_{2} \mathrm{~S}_{2} \mathrm{O}_{3}$ solution. The sections then were post-fixed with $0.05 \%(\mathrm{w} / \mathrm{v}) \mathrm{OsO}_{4}$ in cacodylate buffer for $30 \mathrm{~min}$, dehydrated in a graded series of ethanol $(30-100 \%)$ followed by propylene oxide, and flatembedded in Glycidether 100-based resin (Serva, Heidelberg, Germany). Ultrathin sections were cut and then stained with uranyl acetate and lead citrate. Control vibratome sections were processed as described above, except that the primary antibody was omitted, resulting in no specific 


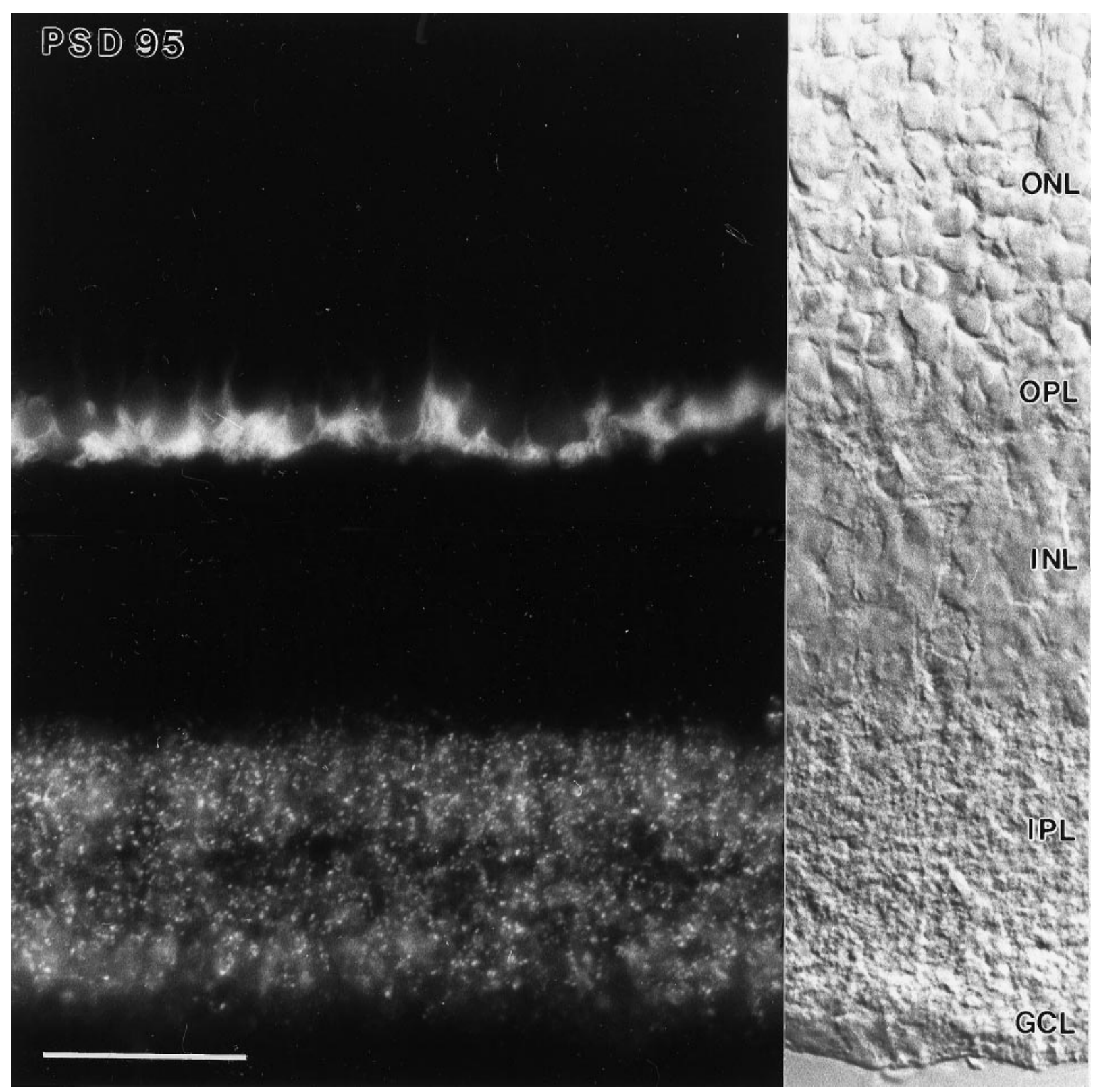

Figure 1. Photomicrograph of a vertical cryostat section through a rat retina that was immunolabeled for PSD-95. The retinal layers are shown in the Nomarski micrograph (right). $O N L$, Outer nuclear layer; $O P L$, outer plexiform layer; $I N L$, inner nuclear layer; $I P L$, inner plexiform layer; $G C L$, ganglion cell layer. PSD-95 immunofluorescence is prominent in the OPL, where the axon terminals of rods, the so-called rod spherules, are labeled intensively. In the IPL punctate immunofluorescence is found, representing a concentration of PSD-95 at synapses. Scale bar, $25 \mu \mathrm{m}$.

staining. Ultrathin sections were examined and photographed with a Zeiss (Oberkochen, Germany) EM10 electron microscope.

\section{Microscopic analysis}

For light microscopic analysis the sections were examined and photographed with a Zeiss photomicroscope (Axiophot, Zeiss), using $40 \times$, $63 \times$, and $100 \times$ objectives and the appropriate fluorescence filter (Alexa 564; Alexa 594: BP 546, FT 580, LP 590; Alexa 488: 450-490, FT 510, LP 520). The fluorescence filters were wedge-corrected, so shifting from one filter to the other did not cause any displacement of the image. No adjustment of focus was necessary when switching from one filter set to another because the objectives (Zeiss, Neofluar) were corrected for at least three different wavelengths. Black and white photomicrographs were taken on Kodak TMY 400 film and color photomicrographs on Kodak Ektachrome color reversal film. To visualize colocalizations of puncta in double-labeled sections, we took black and white micrographs with red and green fluorescence. One of the negatives was printed the correct way; the other negative was turned around for printing. The resulting prints were, therefore, mirror images. They were sectioned along a common border and mounted side by side. This made it easier to visualize colocalizations, because corresponding points were found at equal distances from that border (see Fig. 8).

\section{Quantification of colocalizations of immunofluorescent puncta}

Two micrographs of the sections that were double-labeled for PSD-95/ SAP 102, PSD-95/PSD-93, and PSD-95/NR1, respectively, were taken with the $100 \times$ objective, using red and green fluorescence filters, and printed at a final magnification of $1800 \times$. The immunofluorescent puncta of the micrographs were transferred onto tracing paper. Already this first step has an intrinsic failure rate, because puncta are difficult to detect if they are weakly stained or if they are covered by a cloudy background. To test the positional errors that may have been made, we transferred puncta of the same micrograph twice onto separate transparencies. The two images were superimposed at their correct position, and the number of 

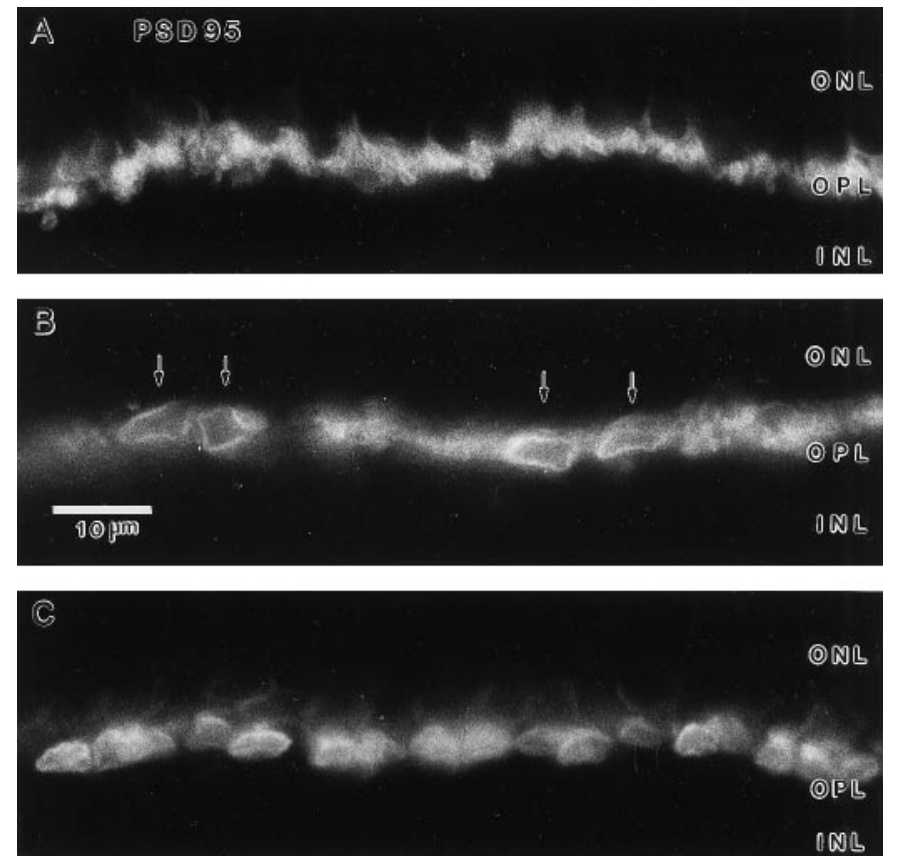

Figure 2. High-power fluorescence micrographs of vertical cryostat sections through rat $(A)$, macaque monkey $(B)$, and tree shrew $(C)$ retinae that were immunostained for PSD-95. $A$, Rod spherules at the outer margin of the OPL are labeled in the rat. B, Four cone pedicles (arrows) and several rod spherules are labeled in the monkey retina. $C$, Exclusively, cone pedicles are labeled in the tree shrew retina. The labeling in rod spherules and cone pedicles is concentrated in their outer membranes.

puncta that coincided was counted. In theory the coincidence rate should be $100 \%$; however, the coincidence rate measured in this way was $85 \pm$ $5 \%$ (mean and SD) in the case of PSD-95/PSD-95; $79.8 \pm 2.8 \%$ in the case of SAP 102/SAP 102; $82.3 \pm 5 \%$ in the case of PSD-93/PSD-93; $81 \pm 5 \%$ in the case of NR1/NR1. Each percentage is the mean of $>1000$ puncta taken from four different sections. The two images also were superimposed randomly, and the number of puncta that coincided was counted. The coincidence rates for random superpositions varied between 18.7 and $22.1 \%$. After these two test trials the two images of the micrographs of the double-labeled sections were superimposed, and the number of coincidences was counted.

We also analyzed the punctate immunofluorescence of double-labeled sections, using confocal microscopy. However, for this particular task we found that conventional microscopy with high-power objectives was superior. Because immunofluorescence in the present experiments is punctate, small changes in focus in a conventional microscope cause the puncta to disappear; therefore, optical sectioning is very precise. The punctate fluorescence acts like the pinhole of the confocal microscope. Because of the scanning mode of the confocal microscope, individual puncta will be represented by several pixels, thereby tending to blur the punctate immunofluorescence. For these reasons conventional microscopy was the method of choice for the present analysis.

\section{RESULTS}

\section{Light microscopic localization of PSD-95}

In vertical sections of the rat retina that were immunostained with the antiserum against PSD-95 (Fig. 1), very intense immunofluorescence was present in the OPL, and comparably moderate immunolabeling was observed in the IPL. It was impossible to capture this enormous difference in intensity between OPL and IPL on a single negative. Figure 1 is therefore a montage printed from two negatives in which the IPL had been exposed eight times longer than the OPL. In the outer retina the immunofluorescence was concentrated in the axon terminals of the photoreceptors; however, weak immunolabeling also was observed in the microscope all along the descending photoreceptor axons. In the IPL the immunofluorescence had a punctate appearance, suggesting that PSD-95 was clustered at synaptic sites.

\section{Localization of PSD-95 in rod spherules and cone pedicles}

The OPL of a rat retina that was immunolabeled for PSD-95 is shown at higher magnification in Figure $2 A$. Immunofluorescence is concentrated in the membrane of rod spherules, which have a diameter of 1-2 $\mu \mathrm{m}$ and which are staggered irregularly at the outer margin of the OPL. Because cones are only a small fraction of the photoreceptors of the rat retina (Szél et al., 1996), no typical cone pedicle is visible in Figure $2 A$. However, when a macaque monkey retina (Fig. $2 B$ ) or a tree shrew retina (Fig. $2 C$ ) was immunolabeled for PSD-95, it became apparent that cone pedicles also express PSD-95. Four cone pedicles of 5-7 $\mu \mathrm{m}$ diameter are interspersed between the rod spherules in the monkey retina (Fig. 2B, arrows). The tree shrew retina is strongly cone-dominated (Müller and Peichl, 1989); consequently, exclusively labeled cone pedicles are found in Figure $2 C$. The localization of PSD-95 in photoreceptor axon terminals was confirmed by electron microscopy (Fig. 3). Figure 3, $A$ and $C$, shows the labeling of cone pedicles and Figure $3, B$ and $D$, shows the labeling of rod spherules. Two presynaptic ribbons are indicated in the cone pedicle of Figure $3 A$ by arrowheads, and three are indicated in Figure $3 B$. Several invaginating postsynaptic processes are marked with stars. Grains of the silver-intensified reaction product are restricted to the cone pedicles, and no traces of labeling are found in horizontal cell or bipolar cell processes contacting the cone pedicles. The same holds true for the two rod spherules illustrated in Figure 3, $B$ and $D$. The spherules containing the ribbons are labeled; the postsynaptic rod bipolar cell dendrites and the horizontal cell processes (stars) are not labeled. In all, 10 cone pedicles and 44 rod spherules were photographed on the electron microscope, and many more were inspected; in no case were bipolar or horizontal cell processes immunoreactive for PSD-95. The light microscopic appearance of labeled cone pedicles and rod spherules suggests a concentration of PSD-95 at the cellular membrane. This is not so evident from the silverintensified reaction product in the electron micrographs. However, if one concentrates instead on the fluffy diaminobenzidine reaction product in Figure $3, A$ and $C$, the aggregation of the labeling along the membrane becomes more apparent. In general, because of the short fixation times that are necessary, the use of a very low concentration of glutaraldehyde in the fixative, and the large amounts of reaction product, the quality of the electron micrographs is compromised somewhat.

\section{Localization of PSD-95 in the IPL of the rat retina}

PSD-95 in the IPL has a punctate appearance (see Fig. 1). Such punctate immunofluorescence suggests a clustering of PSD-95 in synaptic hot spots. This is shown more directly by the electron micrographs in Figure 4. The nine micrographs show the axon terminals of different types of bipolar cells: three OFF cone bipolar cells, which terminate in the outer half of the IPL (see Fig. $3 A-C$ ), three ON cone bipolar cells, which terminate in the lower part of the IPL (see Fig. $3 D-F$ ), and three rod bipolar cells, which terminate close to the ganglion cell layer (see Fig. $3 G-I$ ). Within the bipolar cell axon terminals the presynaptic ribbons are indicated by arrowheads. Usually two postsynaptic processes are opposed to the ribbons; therefore, this synaptic complex has been named a dyad (Dowling and Boycott, 1966). In all nine dyads 


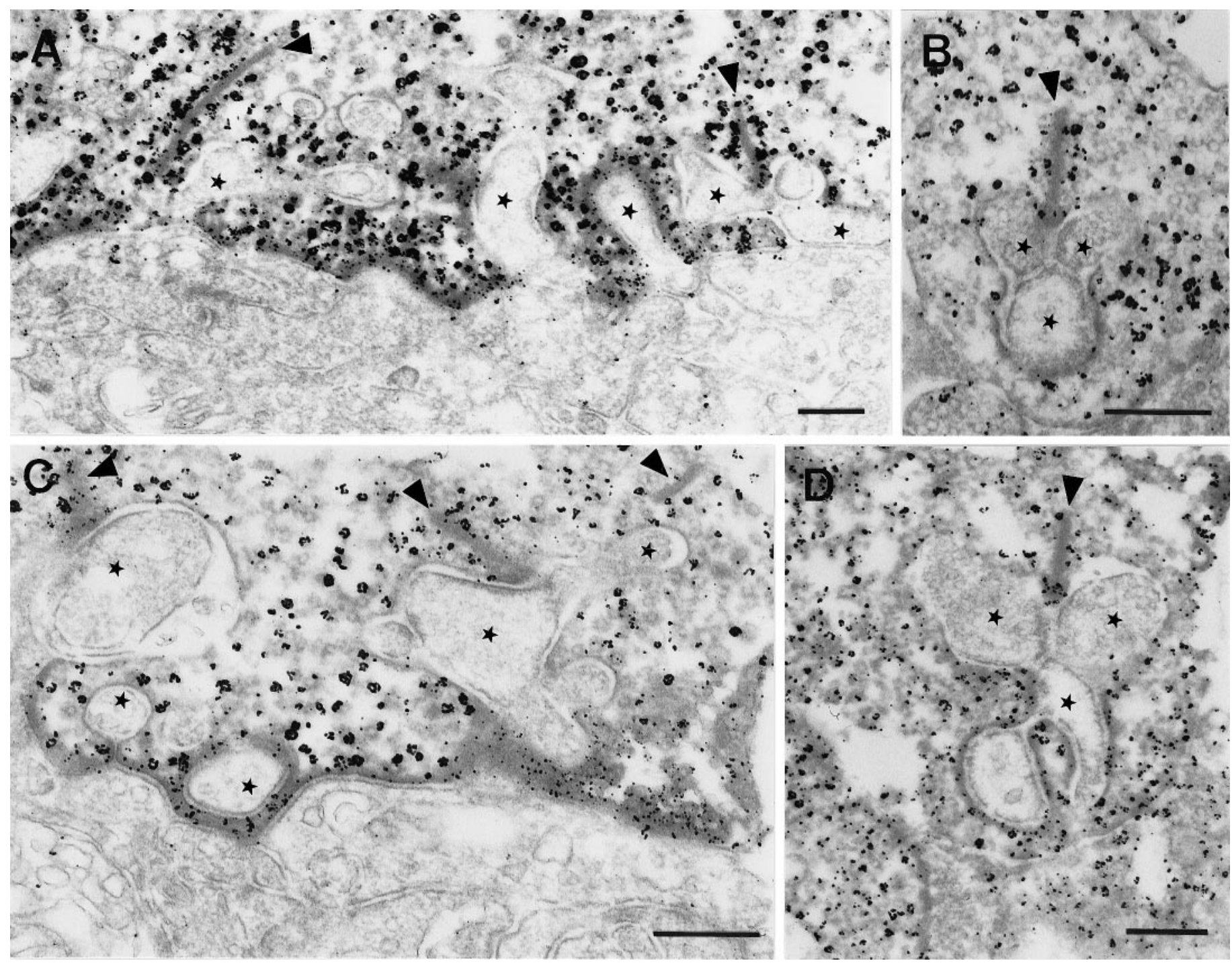

Figure 3. Electron micrographs of sections through cone pedicles $(A, C)$ and rod spherules $(B, D)$ of a rat retina that was immunolabeled for PSD-95. $A$, The labeled cone pedicle base (top half) contains two synaptic ribbons (arrowheads) and receives several invaginating processes (stars) from unlabeled bipolar or horizontal cell dendrites (bottom half). B, Section of the synaptic triad within a labeled rod spherule. The arrowhead indicates the ribbon; the three invaginating processes (stars) are unlabeled. $C$, The labeled cone pedicle base (top half) contains three synaptic ribbons and receives several unlabeled invaginating processes. $D$, Section of the synaptic triad within a labeled rod spherule. The arrowhead indicates the ribbon; the stars mark unlabeled invaginating processes. Scale bars, $0.3 \mu \mathrm{m}$.

illustrated in Figure 4, only one of the postsynaptic processes expressed PSD-95 immunoreactivity. This labeling pattern is reminiscent of the localization of glutamate receptors at the dyads: a given glutamate receptor or subunit is found only in one postsynaptic process at bipolar cell dyads [NR2A subunit, Hartveit et al. (1994); metabotropic glutamate receptors, Brandstätter et al. (1996) and Koulen et al. (1997); kainate receptor subunits, Brandstätter et al. (1997); for review, see Brandstätter et al. (1998)]. In all, 76 bipolar cell ribbon synapses were photographed at the ultrastructural level, and in all cases PSD-95 was restricted to one postsynaptic process of the dyad (15 OFF cone bipolars, 19 ON cone bipolars, and 42 rod bipolars). We did not observe PSD-95 immunoreactivity in the IPL associated with conventional chemical synapses. Because such synapses have amacrine processes as presynaptic partners (Dowling and Boycott, 1966), this makes important predictions with respect to the transmitter receptors that might be associated with PSD-95 at postsyn- aptic sites. Bipolar cells release glutamate, whereas amacrine cells release GABA, glycine, or acetylcholine (Massey and Redburn, 1987; Massey, 1990). PSD-95, which was found postsynaptic to bipolar cells and not to amacrine cells, therefore is associated most likely with glutamate receptors in the IPL.

The postsynaptic clustering of PSD-95 at rod bipolar cell axon terminals (Fig. 4G-I) also was confirmed by light microscopy. Vertical sections of rat retinae were double-labeled for protein kinase $\mathrm{C}(\mathrm{PKC})$ and for PSD-95. The high-power light micrograph in Figure $5 A$ shows the PKC immunoreactive axon terminals of rod bipolar cells in the inner IPL (Greferath et al., 1990). The micrograph in Figure $5 B$ shows the PSD-95 immunoreactive puncta. As indicated by the small arrows in Figure 5, groups of PSD-95 immunoreactive puncta are in register with axonal varicosities of PKC-immunolabeled rod bipolar cells. Individual varicosities are decorated by three to five puncta. In some cases the whole axon terminal could be studied, and between 10 and 15 puncta per rod 

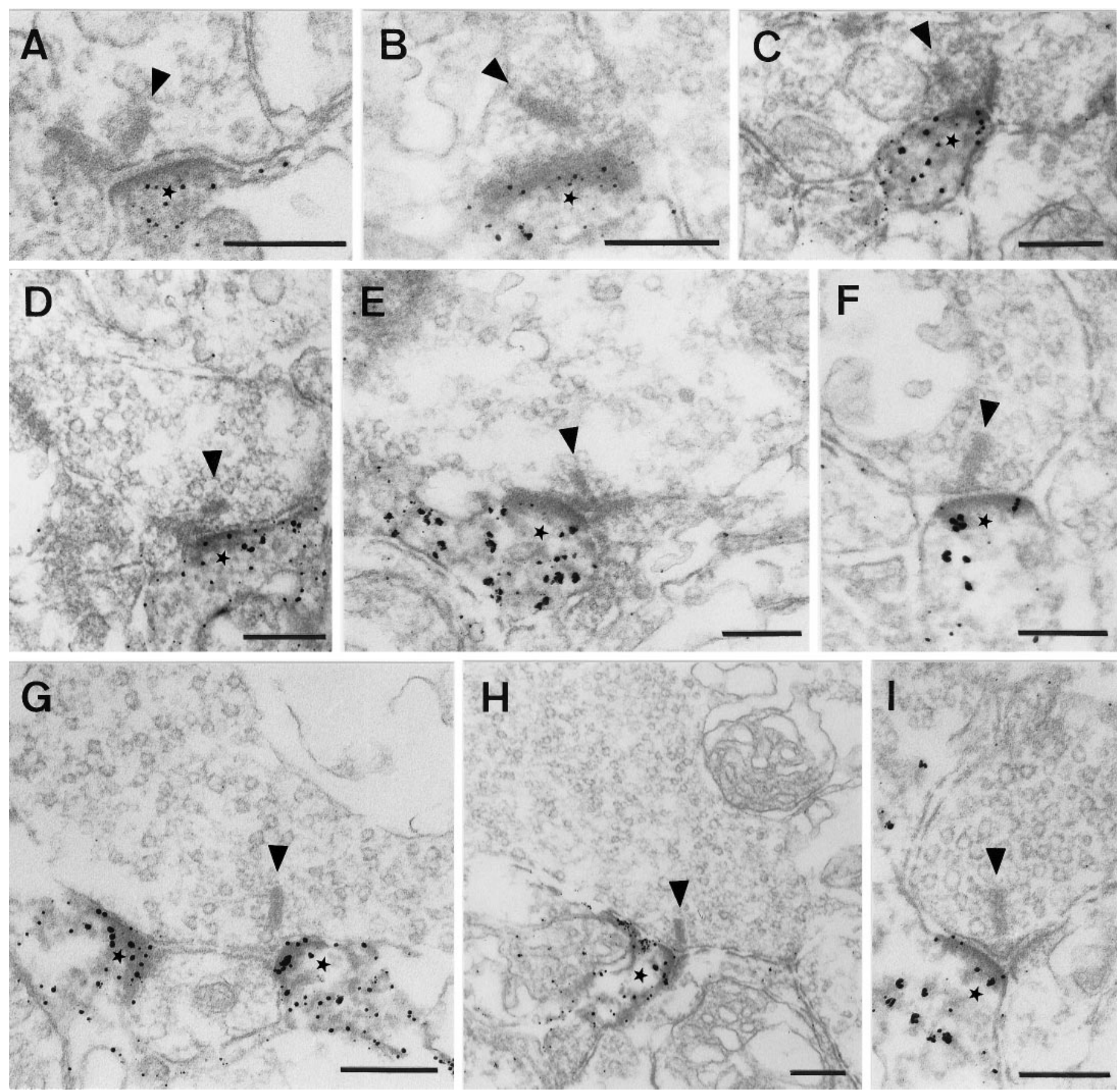

Figure 4. Electron micrographs of sections through the IPL of a rat retina that was immunolabeled for PSD-95. A-C, Shown are the axon terminals of putative OFF cone bipolar cells from the outer part of the IPL. The presynaptic ribbons are marked by arrowheads. Only one of the two postsynaptic processes at this ribbon synapse (dyad) appears to be labeled (star). $D-F$, Shown are the axon terminals of putative ON cone bipolar cells from the inner part of the IPL. The presynaptic ribbons are marked by arrowheads. Labeling is found in only one of the two postsynaptic processes. $G-I$, Shown are the axon terminals of putative rod bipolar cells close to the ganglion cell layer. The presynaptic ribbons are opposed to two postsynaptic processes, of which one (star) appears to be labeled. Scale bars, $0.2 \mu \mathrm{m}$.

bipolar cell axon terminal were found. Chun et al. (1993) estimated that rat rod bipolar cells make $\sim 15$ ribbon synapses. It is, therefore, possible that PSD-95 immunoreactive clusters are found at a major portion of rod bipolar cell ribbon synapses.

\section{Colocalization of PSD-95 and SAP 102 in the rat retina}

The family of synapse-associated proteins that have three PDZ domains includes four closely related proteins: PSD-95/SAP 90 (Cho et al., 1992; Kistner et al., 1993), SAP 97/hdlg (Lue et al.,
1994; Müller et al., 1995), chapsyn-110/PSD-93 (Brenman et al., 1996a; Kim et al., 1996), and SAP 102 (Müller et al., 1996). PSD-95, PSD-93, and SAP 102 have been shown to interact with NMDA receptors in vivo (Kornau et al., 1995; Brenman et al., 1996a,b; Müller et al., 1996). It is interesting, therefore, to determine whether they are localized at the same synapses or whether they are involved with different circuits. In a preceding publication (Koulen et al., 1998) we have studied the retinal distribution 

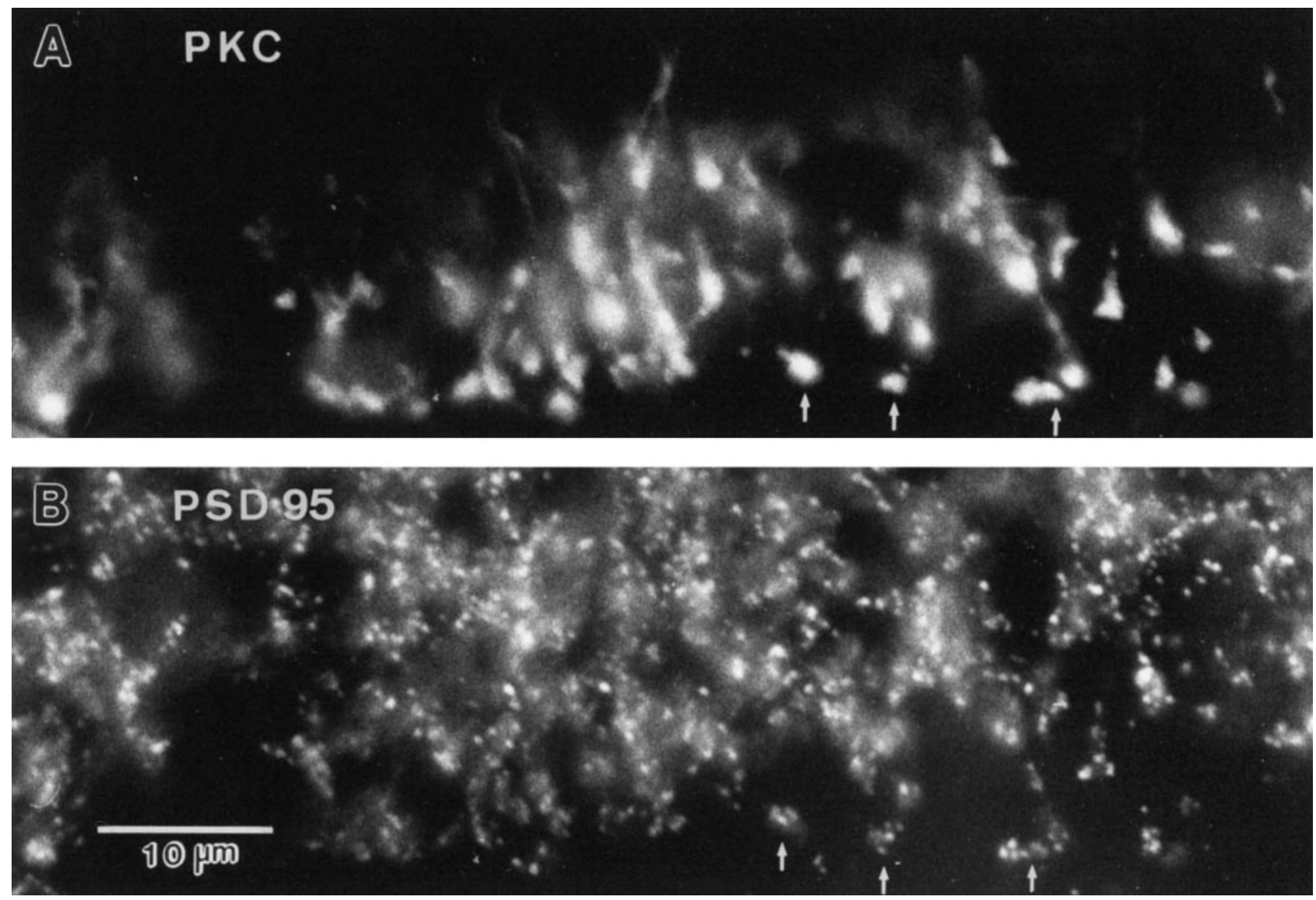

Figure 5. Vertical cryostat section through a rat retina double-labeled for PKC $(A)$ and PSD-95 $(B)$. The fluorescence micrographs show the inner one-third of the IPL. $A$, PKC-immunolabeled axon terminals of rod bipolar cells form small varicosities $2-3 \mu \mathrm{m}$ in diameter. Three are indicated by arrows. B, PSD-95 immunofluorescence is concentrated in "hot spots" $0.25-1 \mu \mathrm{m}$ in diameter. The hot spots are aggregated in groups (arrows) that correspond to the varicosities in $A$. Careful inspection of this high-power light micrograph shows that neighboring hot spots can still be resolved if their distance is $\sim 0.3 \mu \mathrm{m}$.

of SAP 102 in the rat retina. In this study we performed doublelabeling experiments with specific antibodies against PSD-95 and SAP 102, respectively. A section that was double-labeled for both proteins is shown in Figure 6. In the OPL PSD-95 (Fig. 6A) is found in rod spherules, whereas SAP 102 (Fig. 6B) shows a punctate distribution. In the IPL PSD-95 and SAP 102 show a punctate fluorescence, suggesting that both are aggregated in synaptic hot spots. In the optic nerve fiber layer (NFL) SAP 102 (Fig. 6B) is strongly expressed by nerve fiber bundles. The retinal expression patterns of the two synapse-associated proteins therefore are different.

The localizations of PSD-95 and SAP 102 in the OPL are shown in Figure 7 at higher magnification. As described earlier, PSD-95 is localized in rod spherules. This is shown, albeit a bit blurred, in Figure $7 A$. SAP 102 has a punctate appearance in Figure $7 B$. In Figure $7 C$ the SAP 102 immunoreactive puncta have been inserted into the micrograph of PSD-95-labeled rod spherules at their correct position, and it becomes apparent that the puncta are encircled by the rod spherules. This is consistent with the localization of PSD-95 and SAP 102 as revealed by electron microscopy. PSD-95 is found in photoreceptor terminals (see Fig. 3), whereas SAP 102 has been localized to invaginating processes at photoreceptor ribbon synapses and in particular to horizontal cell processes (Koulen et al., 1998). PSD-95 and SAP 102 therefore are found at opposite sides of the photoreceptor synapses and most likely fulfill different functions there.
In the IPL both PSD-95 labeling and SAP 102 labeling have a punctate appearance (see Fig. 6A,B), suggesting that they are localized in synaptic hot spots. This is supported by the electron micrographs in Figure 3, which show that PSD-95 is aggregated in one of the postsynaptic processes at bipolar cell dyads. Exactly the same localization has been described for SAP 102 (Koulen et al., 1998), which raises the interesting question as to whether they are found in the same process associated with the dyad.

Micrographs of the IPL of a section that was double-labeled for PSD-95 and SAP 102 are shown in Figure $8 A$. To visualize possible colocalizations, we have printed mirror images of the PSD-95 and the SAP 102 immunoreactivities side by side in Figure $8 A$. A comparison of puncta across the midline shows that many are at symmetrical positions, which suggests they are colocalized. However, the white blur in Figure $8 \mathrm{~A}$, which is caused partly by out-of-focus puncta and partly by the uneven thickness of the section, makes it difficult to compare the puncta across the midline. The puncta of Figure $8 A$ therefore are shown in isolation in Figure $8 B$.

Figure $8 B$ contains 247 puncta immunoreactive for PSD-95 and 198 puncta immunoreactive for SAP 102. It is possible that the different numbers reflect the better staining quality of PSD-95. In all, 134 puncta $(68 \%)$ were found to be colocalized, and these are in isolation shown in Figure $8 C$. Their symmetric positions with respect to the midline become apparent. This result also was analyzed more quantitatively, as described in Materials and 

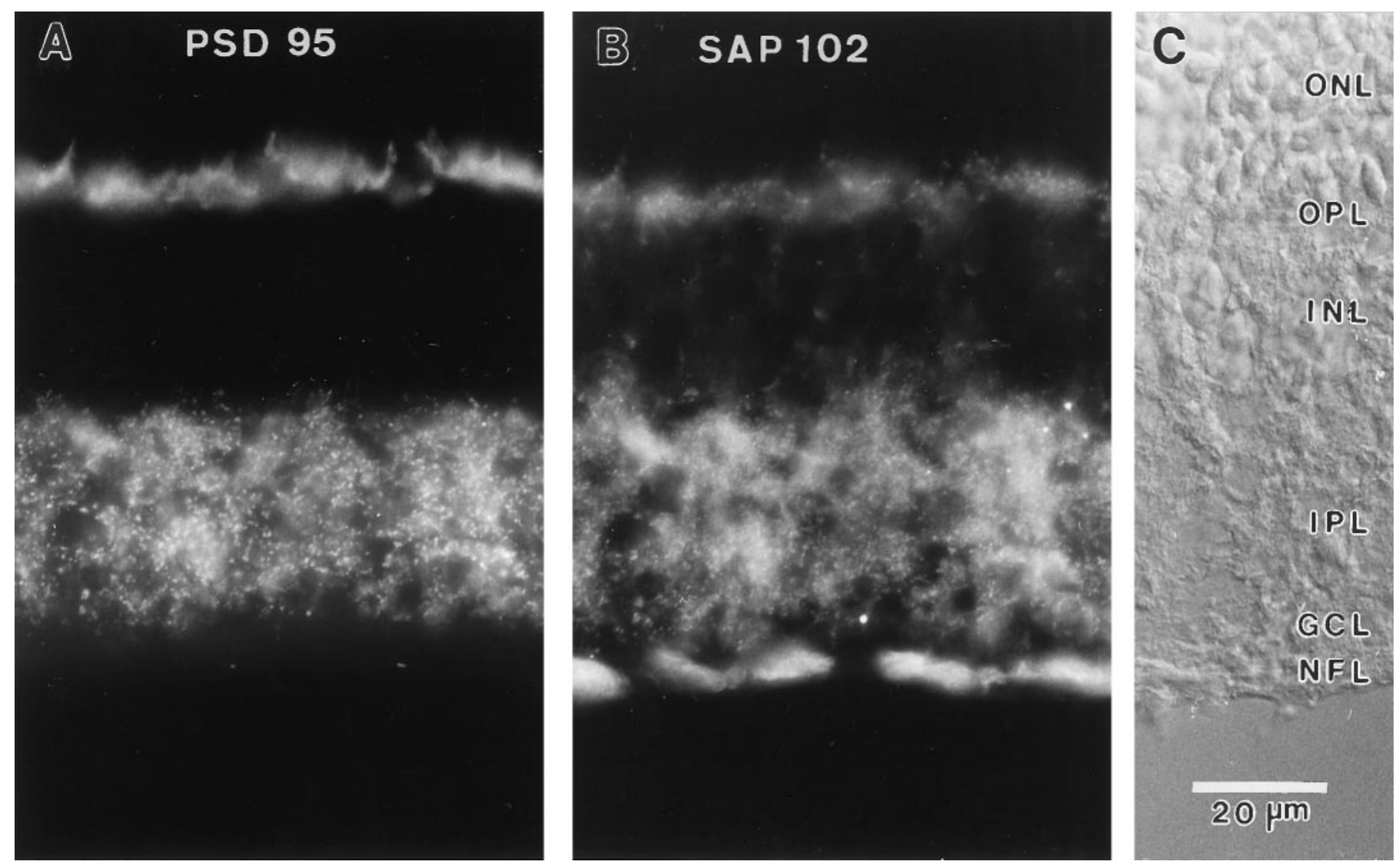

Figure 6. Vertical cryostat section through a rat retina double-labeled for PSD-95 $(A)$ and SAP $102(B)$. The Nomarski micrograph in $C$ shows the retinal layers. $A$, PSD-95 immunofluorescence is most prominent in rod spherules of the OPL. In the IPL the fluorescence is concentrated in "hot spots." $B$, SAP 102 immunofluorescence is sparse in the OPL, and weak extrasynaptic labeling is present in the INL; in the IPL the labeling is concentrated in hot spots, and prominent labeling is also present in the optic nerve fiber layer $(N F L)$. Because of the short fixation the tissue was very soft, and the cryostat sections were of uneven thickness and appeared to be ruptured.

Methods. High-power micrographs were printed, and the puncta were transferred onto tracing paper. When puncta of the same SAP 102-labeled section were transferred twice onto separate sheets of tracing paper and when the coincidences were counted, only $79.8 \pm 2.8 \%$ instead of the theoretical $100 \%$ was found. The reason for this lower count is the jitter introduced by tracing the puncta and the uneven staining of the sections. When the drawings of the SAP 102-labeled puncta were superimposed onto the drawings of a PSD-95-labeled puncta, $68 \pm 1 \%$ of the puncta coincided. However, allowing for the intrinsic failure rate, the actual colocalization of SAP 102 and PSD-95 must be higher than the $68 \%$ measured, and we therefore conclude that in most instances SAP 102 and PSD-95 are found in the same postsynaptic densities within the IPL. The optical resolution for neighboring puncta in the light micrographs was found to be $0.3 \mu \mathrm{m}$ (see, for example, Fig. $5 B$ ), which is good enough to decide whether SAP 102 and PSD-95 label the same processes at the dyads or two adjacent processes. The close correspondence of the puncta suggests that SAP 102 and PSD-95 are present in the same processes.

\section{Colocalization of PSD-95 and PSD-93 in the retina}

PSD-93 has been cloned recently (Brenman et al., 1996a), and its overall amino acid identity with PSD-95 is 70\%. More importantly, like SAP 102 and PSD-95, PSD-93 contains three PDZ domains, suggesting comparable functions. However, in the cerebellum PSD-93 was found postsynaptically in Purkinje cells, whereas PSD-95 was found presynaptically (Brenman et al., 1996b; Laube et al., 1996), suggesting different functions of the protein. We therefore looked in colocalization experiments (Fig. 9) for the expression of PSD-95 and PSD-93 in the mammalian retina. As can be seen in the low-power micrographs (Fig. 9A,B), PSD-95 and PSD-93 have a similar distribution both in the OPL and in the IPL. In the OPL the rod spherules show a prominent expression. In the IPL punctate immunofluorescence is found for both PSD-93 and PSD-95. The only qualitative difference we could detect was an expression of PSD-93 in the optic nerve fiber layer (Fig. 9B), which was absent in the PSD-95 immunofluorescence (Fig. 9A). A similar staining of the optic nerve fiber layer also was observed in the case of SAP 102 (see Fig. 6). High-power micrographs of the puncta labeled in the IPL are shown in Figure $8 D$. They are printed as mirror images; hence puncta at symmetric positions with respect to the midline represent colocalizations. It is obvious that many such symmetric puncta are present in Figure $8 D$. To show this in better detail, we have drawn the puncta in isolation in Figure $8 E$. In Figure $8 F$, finally, only those puncta that are at symmetric positions are inserted. Figure $8 E$ contains 221 PSD-93 and 294 PSD-95 immunoreactive puncta. Of these, $165(75 \%)$ were found to be colocalized (see Fig. $8 F$ ).

This result also was analyzed more quantitatively, as described before. Superposition of PSD-93 immunoreactive puncta drawn from identical micrographs resulted in a $82.3 \pm 5 \%$ coincidence rate instead of the theoretical $100 \%$. When drawings of PSD-93labeled puncta were superimposed onto the drawings of PSD-95- 

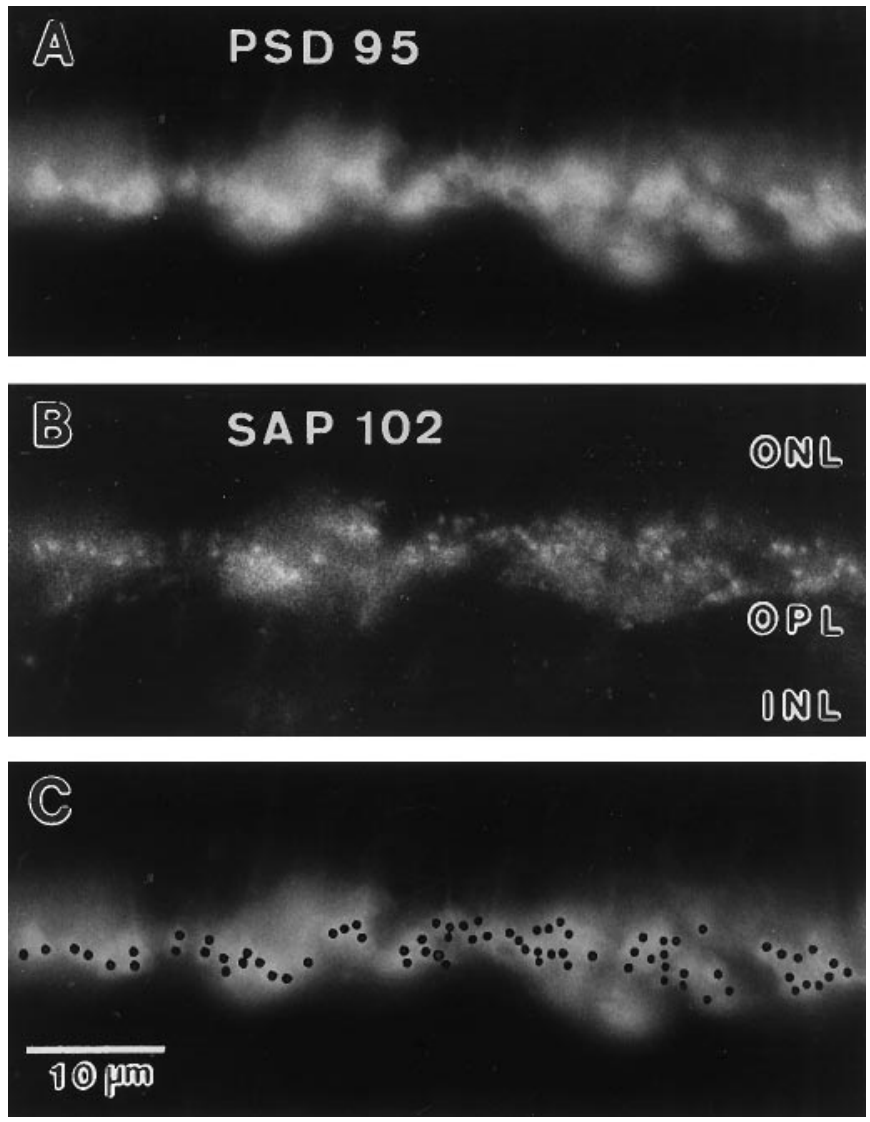

Figure 7. High-power fluorescence micrograph of a vertical section through the OPL of a rat retina that was double-labeled for PSD-95 $(A)$ and SAP $102(B)$. $A$, Slightly blurred rod spherules express PSD-95 immunofluorescence. $B$, Small puncta express SAP 102 immunoreactivity. We previously have shown by electron microscopy that these puncta represent terminals of horizontal cell processes (Koulen et al., 1998). $C$, The same micrograph as in $A$, with the puncta, taken from $B$, inserted as black dots.

labeled puncta, a coincidence rate of $65 \pm 8 \%$ was found. This leads to the conclusion that PSD-93 and PSD-95 are aggregated at the same synapses in the IPL.

\section{Colocalization of PSD-95 and NMDA receptors}

The expression of NMDA receptors (NRs) in mammalian retinae has been studied by in situ hybridization (Brandstätter et al., 1994; Watanabe et al., 1994). In the ganglion cell layer virtually every ganglion cell or displaced amacrine cell expressed the receptor subunits $\mathrm{NR} 1, \mathrm{NR} 2 \mathrm{~A}, \mathrm{NR} 2 \mathrm{~B}$, and $\mathrm{NR} 2 \mathrm{C}$. In the inner nuclear layer the receptor subunit NR1 was distributed homogeneously and therefore possibly is expressed by all cell types in this layer. The NR2A, NR2B, and NR2C subunits were expressed in subsets of amacrine cells; the NR2C subunit also was found at the location of bipolar cell perikarya (Brandstätter et al., 1994). The NR1, the NR2A, and the NR2D subunits have been localized immunocytochemically (Hartveit et al., 1994; Wenzel et al., 1997a; Lo et al., 1998; Wong-Riley, 1998). Strong punctate NR2A immunofluorescence was observed in the IPL, and the application of electron microscopy showed that the NR2A subunit is aggregated at postsynaptic sites (Hartveit et al., 1994). In the case of the NR2D subunit, Wenzel et al. (1997a) reported extrasynaptic labeling of rod bipolar cells. NR1 immunoreactivity was observed in ganglion cells, in amacrine cells, and in both plexi- form layers (Wong-Riley et al., 1998). Lo et al. (1998) reported the presence of four different splice variants of NR1 and described the immunocytochemical labeling of rod bipolar and Müller cells.

In other parts of the CNS, SAP 102 or PSD-95 has been found to be associated with NMDA receptors (Kornau et al., 1995; Müller et al., 1996; Niethammer et al., 1996). The NR1 subunit is the most widely distributed NMDA receptor subunit in the brain (Hollmann and Heinemann, 1994) and in the retina (Brandstätter et al., 1994). Only when they are coexpressed with the NR1 subunit do NR2 subunits form functioning channels in artificial expression systems. This suggests that NMDA receptors at synapses contain either homomeric combinations of NR1 or heteromeric combinations of NR1 and other subunits (Hollmann and Heinemann, 1994). Therefore, double-labeling experiments were performed for NR1 and PSD-95 to show the possible colocalization of NMDA receptors and PSD-95 in the mammalian retina. We found a high degree at colocalization between PSD-95 and NR1. However, it should be emphasized that this may not represent the direct binding of PSD-95 with NR1; rather, it may be the consequence of the association of NR1 with NR2, which has been shown recently to be the binding partner of PSD-95 (Kim et al., 1995; Kornau et al., 1995).

The results are shown in Figure 10. The most prominent labeling for the NR1 subunit is found in the IPL. The labeling there is punctate (Fig. 10B), with some indication of separate layers. The perikarya of ganglion cells and possibly of displaced amacrine cells are labeled in the ganglion cell layer. Some amacrine cells (Fig. 10B, arrow) are labeled distinctly; others are labeled more faintly. Weak labeling is also present in the OPL and in some cell bodies at the outer margin of the inner nuclear layer (Fig. 10B, arrowhead). Clearly, this weak labeling in the OPL is not related to the prominent labeling of rod spherules and cone pedicles by PSD-95 (Fig. 10 $A$ ).

To show the possible colocalization in the IPL, we have shown high-power micrographs of PSD-95 and the NR1 subunit in Figure $8 G$. They are printed as mirror images for better visualization of colocalizations. Many puncta appear at symmetrical positions with respect to the midline. This becomes more obvious from Figure $8 \mathrm{H}$, where the puncta are shown in isolation: 332 PSD-95 immunoreactive puncta are opposed to $221 \mathrm{NR} 1 \mathrm{immu}-$ noreactive puncta. In Figure $8 I$ only the 148 puncta that would coincide are shown, and this suggests that $67 \%$ of the NR1 puncta also express PSD-95.

As described before, the colocalizations also were measured more quantitatively by transferring puncta from double-labeled sections onto tracing paper and creating superpositions of the images. When puncta of the same NR1-labeled micrograph were transferred twice onto separate sheets of tracing paper and when the coincidences were counted, this result should have been a coincidence rate of $100 \%$; however, only $81 \pm 5 \%$ was found. The staining quality of the NR1 puncta and the resulting positional errors cause this deviation from the theoretical prediction. When the NR1 puncta were superimposed onto the PSD-95 puncta at their correct position, $65 \pm 3 \%$ of the puncta coincided. This shows that PSD-95 is a constituent of the postsynaptic density in the majority of NR1-expressing synapses.

\section{DISCUSSION}

\section{Localization of PSD-95 in the outer retina}

There was a strong expression of PSD-95 in both cone and rod photoreceptors. Labeling was observed all along their descending 

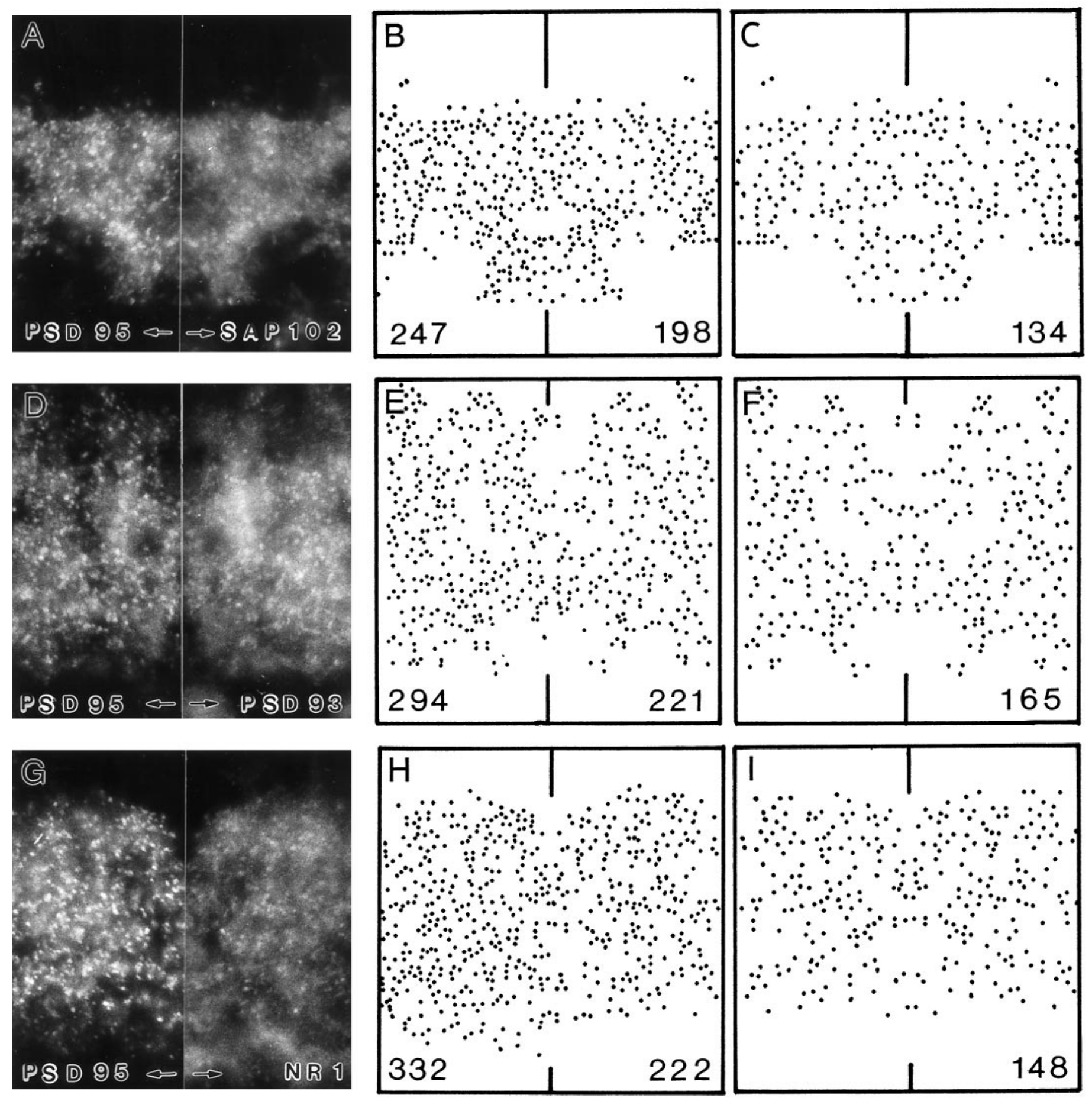

Figure 8. The high-power photomicrographs (left column, $A, D, G$ ) show the IPL of double-labeled sections through rat retinae. PSD-95 immunofluorescence is shown in the left side of each micrograph. Immunofluorescence for SAP $102(A)$, PSD-93 $(D)$, and NR1 $(G)$ are shown on the right side and are printed as mirror images. The midline is cut along a common border, and puncta at symmetric positions with respect to the midline represent colocalizations. Drawings of all puncta are shown in the middle column $(B, E, H)$. Drawings of puncta at symmetrical positions, representing colocalizations, are shown in the right column $(C, F, I)$. The numbers of the labeled puncta are inserted. Each frame represents $40 \times 40 \mu \mathrm{m}$.

axons but was most prominent in cone pedicle and rod spherule membranes. We have never observed before, with any antigen, such a strong fluorescent signal. The labeling was confined to the presynaptic site of the photoreceptor synapse; however, it was not restricted there to the region around the ribbons but was found all over the pedicle or spherule. One might argue that the invaginating processes of horizontal cells provide a feedback signal, and thus the PSD-95 in photoreceptors would be located postsynaptically to horizontal cells (for review, see Piccolino, 1995; Yazulla, 1995). We are not in favor of this view, because PSD-95 is not clustered at the contacts between photoreceptors and horizontal cell terminals but is found all around rod spherules and cone pedicles. 

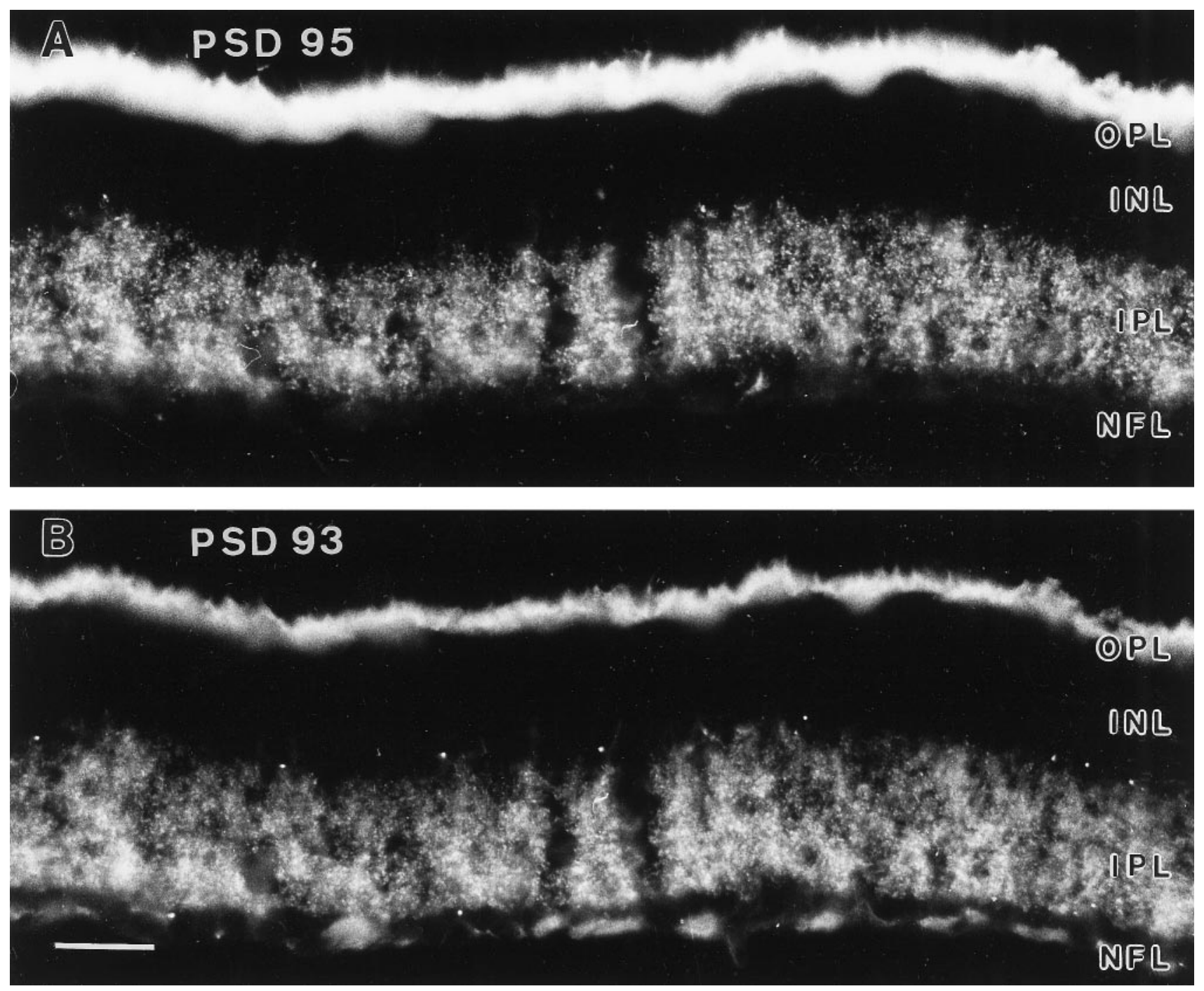

Figure 9. Vertical cryostat section through a rat retina double-labeled for PSD-95 $(A)$ and PSD-93 $(B)$. The labeling in the OPL is much more prominent for PSD-95; however, close inspection in the microscope shows that both PSD-95 and PSD-93 label rod spherules. Punctate labeling is present in the IPL both in $A$ and $B$, and comparison of the puncta suggests that they are colocalized. This is demonstrated in more detail in Figure $8 D$. The optic nerve fiber layer expresses PSD-93 (labeling at the bottom of $B$ ), but not PSD-95. Because of the short fixation the IPL appears to be ruptured. Scale bar, $25 \mu \mathrm{m}$.

A variety of $\mathrm{K}^{+}$channels, $\mathrm{Ca}^{2+}$-activated chloride channels, and $\mathrm{Ca}^{2+}$ channels has been described in photoreceptor inner segments (for review, see Barnes, 1994), and they are candidates to be associated with PSD-95. However, recent immunocytochemical localizations of Shaker-like $\mathrm{K}^{+}$channels did not describe a labeling of cone pedicle or rod spherule membranes (Klumpp et al., 1995a,b). Therefore, PSD-95 may not be associated in the photoreceptor terminals with Shaker-like $\mathrm{K}^{+}$channels as has been found in other parts of the CNS (Kim et al., 1995; Laube et al., 1996). Similarly, an association of PSD-95 with NMDA receptors in photoreceptor terminals can be excluded. We did not observe any significant staining of photoreceptors with the antibodies against the NR1 subunit (see Fig. 10). A comparable negative result was found for the NR2A subunit (Hartveit et al., 1994), the NR2B subunit (our unpublished observations), or the NR2D subunit (Wenzel et al., 1997a). Hence proteins other than NMDA receptors or $\mathrm{K}^{+}$channels may be associated with PSD-95 in photoreceptor terminals. Neuronal nitric oxide synthase (nNOS) has been found to be colocalized with PSD-95 in many neuronal populations (Brenman et al., 1996b). NADPH diaphorase histochemistry, an indicator of nNOS-containing neurons, applied to the retina did not reveal a preferential staining of photoreceptor terminals (Sagar, 1986). Recently, macaque monkey retinal sections have been immunostained for nNOS (Wong-Riley et al., 1998), and strong immunoreactivity was observed in the OPL. Unfortunately, the resolution in the published micrographs is too low to detect the labeling of cone pedicles or rod spherules. Our lab recently has studied the calcium extrusion from photoreceptor terminals and found that this is mediated preferentially by the plasma membrane calcium ATPase, which was enriched in rod and cone terminals [see Morgans et al. (1998), their Fig. 1B]. However, in cone pedicles only the neck region showed strong staining, whereas the synaptic region, the pedicle base, was labeled only weakly. The pedicle base was strongly immunoreactive for $\mathrm{Ca}^{2+}$ channels. This shows that we may have to consider more exotic partners to be associated with PSD-95 in photoreceptor terminals or that PSD-95 may fulfill separate roles in different compartments within the termi- 

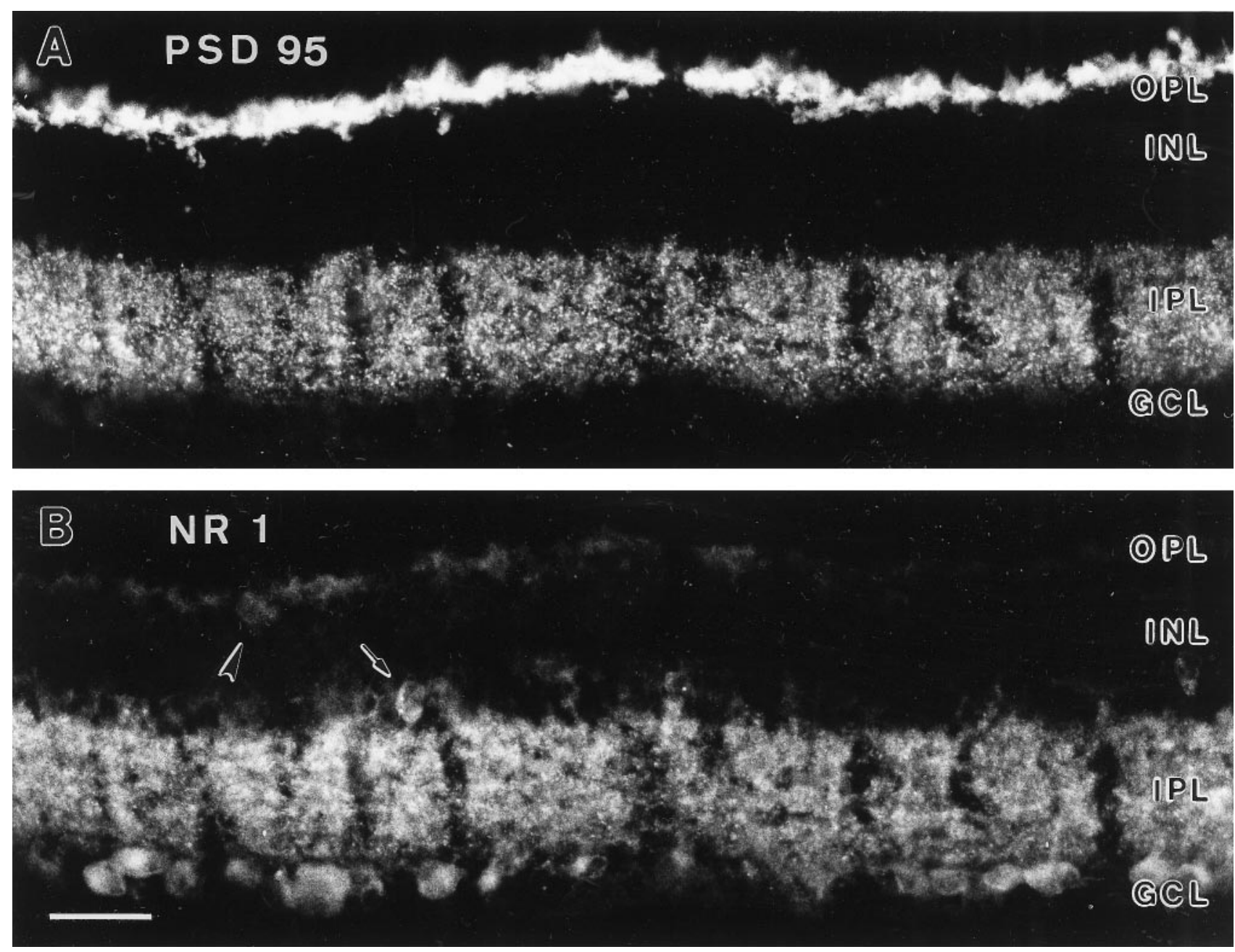

Figure 10. Vertical cryostat section through a rat retina double-labeled for PSD-95 $(A)$ and the NR1 subunit of the NMDA receptor $(B)$. In addition to the punctate labeling in the IPL, NR1 immunofluorescence is also present in cell bodies of the ganglion cell layer and in some amacrine cells (arrow). Weak and sparse labeling is also present in the OPL; a putative horizontal cell body is indicated by the arrowhead. Because of the short fixation the IPL appears to be ruptured. Scale bar, $25 \mu \mathrm{m}$.

nals. At the pedicle neck it could be associated with one sort of molecule and at the pedicle base with some other type.

\section{Localization of PSD-95 in the inner retina}

The distribution of PSD-95 in the IPL had a punctate appearance, which was shown by electron microscopy to represent a clustering of PSD-95 in terminals postsynaptic to bipolar cell ribbon synapses (dyads). As a rule, only one of the two postsynaptic members at the dyad was labeled. Because of the short fixation time and the low concentration of glutaraldehyde in the fixative, the tissue preservation was compromised. Therefore, we were not able to decide whether at cone bipolar cell dyads both ganglion and amacrine cell dendrites were labeled (Dowling and Boycott, 1966). Similarly, we could not recognize the two postsynaptic processes at rod bipolar cells, the AI and AII amacrine cells (Famiglietti and Kolb, 1975). However, the colocalization of PSD-95 immunoreactive puncta with NR1 immunoreactive puncta could provide the answer. In Figure $10 \mathrm{~B}$ amacrine and ganglion cell perikarya were found to be immunoreactive for the NR1 subunits. They almost certainly represent the parent cell bodies for the NR1 puncta in the IPL. Consequently, we suggest that both amacrine and ganglion cells may express PSD-95 at the synapses they receive from bipolar cells.
Double-labeling experiments were performed to determine whether PSD-95 participates in the clustering of NMDA receptors in the retina, as has been suggested by biochemical studies and immunostaining in other parts of the brain (Kim et al., 1995; Kornau et al., 1995; Niethammer et al., 1996). The NR1 subunit is not only the most abundant subunit in the brain (Wenzel et al., $1995,1997 b)$ but is also a necessary constituent of functioning NMDA receptor channels (Hollmann and Heinemann, 1994). Although the direct interaction between NMDA receptor channels and PSD-95 is supposed to be through the NR2 subunits (Kennedy, 1997), such channels also must contain NR1 subunits. After many failures with other fixation protocols we finally succeeded in immunolabeling retinal sections for the NR1 subunit by using a carbodiimide fixation. This resulted in prominent punctate (synaptic) labeling in the IPL and in weaker extrasynaptic labeling of the parent cell bodies. This is in contrast to the widely distributed and diffuse labeling that Wong-Riley et al. (1998) reported for the NR1 subunit in the primate retina. It also differs from the labeling rod bipolar and Müller cells reported by Lo et al. (1998) for the mouse retina. This difference might be caused by the different fixation protocols that were applied and by different specificities of the antibodies that were used. Our double-labeling 
experiments for PSD-95 and the NR1 subunit showed that the majority of NR1 immunoreactive clusters also expressed punctate PSD-95 immunoreactivity. Unfortunately, we cannot be more precise at present for the following reason. The punctate staining for PSD-95 was always crisp, and it was easy to recognize and draw the puncta. The definition of puncta was not so clear in the case of NR1 immunolabeling (see Fig. 8G). More puncta were found that express PSD-95 immunoreactivity, and fewer expressed NR1 immunoreactivity. Whether this reflects merely the staining quality or whether PSD-95 is associated in the IPL with channels other than NMDA receptors is presently uncertain. It is also unclear whether there is a subpopulation of NMDA receptors that is not associated with PSD-95. However, only one of the two postsynaptic members at the bipolar cell ribbon synapses expressed PSD-95. Both postsynaptic processes must express glutamate receptors, which leads to the conclusion that PSD-95 is associated only with a subset of the glutamate receptors.

\section{Localization of PSD-95, PSD-93, and SAP 102 in the mammalian retina}

In the IPL punctate immunolabeling was found for all three synapse-associated proteins. This suggests that all three are aggregated at synaptic sites. A postsynaptic localization has been shown by electron microscopy in our previous study for SAP 102 (Koulen et al., 1998) and in the present study for PSD-95. Because most of the PSD-93 immunoreactive puncta are colocalized with PSD-95, this also implies a postsynaptic localization of PSD-93. The colocalization experiments PSD-95/PSD-93, PSD95/SAP 102, and PSD-95/NR1 suggest that in many postsynaptic sites these proteins are aggregated together. This raises the interesting question as to why there are three proteins that are structurally and functionally so similar in the same postsynaptic density and suggests that they fulfill different roles. This is supported further if one compares the localization of the three proteins outside the IPL.

In the OPL PSD-95 is strongly expressed in the photoreceptor terminals. PSD-93 also is found in photoreceptor terminals, but the intensity of the fluorescence is substantially lower than for PSD-95 (compare Fig. 9, $A$ with $B$ ). SAP 102 was found in a postsynaptic position in the OPL (see Fig. 7). A weak expression of SAP 102 also was found in extrasynaptic membranes of cells in the inner nuclear layer, where it possibly is associated with $\mathrm{K}^{+}$ channels (Koulen et al., 1998). A difference also was observed with respect to the labeling of the optic nerve fibers. PSD-93 and SAP 102 were expressed in the nerve fiber layer, whereas PSD-95 could not be detected there. A possible function of PSD-93 and SAP 102 in the nerve fiber layer is the anchoring of $\mathrm{K}^{+}$channels. The nerve fibers in the retina are not myelinated, and a smooth distribution of $\mathrm{K}^{+}$channels along the fibers therefore is expected, which is in agreement with the labeling pattern observed for SAP 102 (see Fig. 6B) and PSD-93 (see Fig. 9).

We also have studied the postnatal development of PSD-95 in the rat retina by light microscopy. The punctate immunofluorescence was observed immediately after birth (P0) and apparently precedes the formation of ribbon synapses (Sassoè-Pognetto and Wässle, 1997). This would suggest that PSD-95 not only is involved with the aggregation of transmitter (NMDA) receptors at synaptic sites or the modulation of synapses but also plays an important role in the generation of synapses.

\section{REFERENCES}

Barnes S (1994) After transduction: response shaping and control of transmission by ion channels of the photoreceptor inner segment. Neuroscience 58:447-459.

Brandstätter JH, Hartveit E, Sassoè-Pognetto M, Wässle H (1994) Expression of NMDA and high-affinity kainate receptor subunit mRNAs in the adult rat retina. Eur J Neurosci 6:1100-1112.

Brandstätter JH, Koulen P, Kuhn R, van der Putten H, Wässle H (1996) Compartmental localization of a metabotropic glutamate receptor (mGluR7): two different active sites at a retinal synapse. J Neurosci 16:4749-4756.

Brandstätter JH, Koulen P, Wässle H (1997) Selective synaptic distribution of kainate receptor subunits in the two plexiform layers of the rat retina. J Neurosci 17:9298-9307.

Brandstätter JH, Koulen P, Wässle H (1998) Diversity of glutamate receptors in the mammalian retina. Vision Res 38:1385-1397.

Brenman JE, Christopherson KS, Craven SE, McGee AW, Bredt DS (1996a) Cloning and characterization of postsynaptic density 93, a nitric oxide synthase interacting protein. J Neurosci 16:7407-7415.

Brenman JE, Chao DS, Gree SH, McGee AW, Craven SE, Santillano DR, Huang F, Xia H, Peters MF, Froehner SC, Bredt DS (1996b) Interaction of nitric oxide synthase with the synaptic density protein PSD-95 and $\alpha-1$ syntrophin mediated by PDZ motifs. Cell 84:757-767.

Cho K-O, Hunt CA, Kennedy MB (1992) The rat brain postsynaptic density fraction contains a homolog of the Drosophila discs-large tumor suppressor protein. Neuron 9:929-942.

Chun M-H, Han S-H, Chung J-W, Wässle H (1993) Electron microscopic analysis of the rod pathway of the rat retina. J Comp Neurol 332:421-432.

Dowling JE, Boycott BB (1966) Organization of the primate retina: electron microscopy. Proc R Soc Lond [Biol] 166:80-111.

Famiglietti EV, Kolb H (1975) A bistratified amacrine cell and synaptic circuitry in the inner plexiform layer of the retina. Brain Res 84:293-300.

Gomperts SN (1996) Clustering membrane proteins: it's all coming together with the PSD-95/SAP90 protein family. Cell 84:659-662.

Greferath U, Grünert U, Wässle H (1990) Rod bipolar cells in the mammalian retina show protein kinase C-like immunoreactivity. J Comp Neurol 301:433-442.

Grünert U, Wässle H (1993) Immunocytochemical localization of glycine receptors in the mammalian retina. J Comp Neurol 335:523-537.

Hartveit E, Brandstätter JH, Sassoè-Pognetto M, Laurie DJ, Seeburg PH, Wässle H (1994) Localization and developmental expression of the NMDA receptor subunit NR2A in the mammalian retina. J Comp Neurol 348:570-582.

Hollmann M, Heinemann S (1994) Cloned glutamate receptors. Annu Rev Neurosci 17:31-108.

Hunt CA, Schenker LJ, Kennedy MB (1996) PSD-95 is associated with the postsynaptic density and not with the presynaptic membrane at forebrain synapses. J Neurosci 16:1380-1388.

Irie M, Hata Y, Takeuchi M, Ichtchenko K, Toyoda A, Hirao K, Takai Y, Rosahl TW, Südhof TC (1997) Binding of neuroligins to PSD-95. Science 277:1511-1515.

Kennedy MB (1997) The postsynaptic density at glutamatergic synapses. Trends Neurosci 20:264-268.

Kim E, Niethammer M, Rothschild A, Jan YN, Sheng M (1995) Clustering of Shaker-type $\mathrm{K}^{+}$channels by interaction with a family of membrane-associated guanylate kinases. Nature 378:85-88.

Kim E, Cho KO, Rothschild A, Sheng M (1996) Heteromultimerization and NMDA receptor-clustering activity of chapsyn-110, a member of the PSD-95 family of proteins. Neuron 17:103-113.

Kirsch J, Betz H (1998) Glycine-receptor activation is required for receptor clustering in spinal neurons. Nature 392:717-720.

Kistner U, Wenzel BM, Veh RW, Cases-Langhoff C, Garner AM, Appeltauer U, Voss B, Gundelfinger ED, Garner CC (1993) SAP 90, a rat presynaptic protein related to the product of the Drosophila tumor suppressor gene $d l g-A$. J Biol Chem 268:4580-4583.

Klumpp DJ, Song EJ, Pinto LH (1995a) Identification and localization of $\mathrm{K}^{+}$channels in the mouse retina. Vis Neurosci 12:1177-1190.

Klumpp DJ, Song EJ, Ito S, Sheng MH, Jan LY, Pinto LH (1995b) The Shaker-like potassium channels of the mouse rod bipolar cell and their contributions to the membrane current. J Neurosci 15:5004-5013.

Kornau H-C, Schenker LT, Kennedy MB, Seeburg PH (1995) Domain interaction between NMDA receptor subunits and the postsynaptic density protein PSD-95. Science 269:1737-1740. 
Koulen P, Kuhn R, Wässle H, Brandstätter JH (1997) Group I metabotropic glutamate receptors mGluR $1 \alpha$ and $\operatorname{mGluR} 5 \alpha$ : localization in both synaptic layers of the rat retina. J Neurosci 17:2200-2211.

Koulen P, Garner CC, Wässle H (1998) Immunocytochemical localization of the synapse-associated protein SAP 102 in the rat retina. J Comp Neurol 397:326-336.

Laube G, Röper J, Pitt JC, Sewing S, Kistner U, Garner CC, Pongs O, Veh RW (1996) Ultrastructural localization of Shaker-related potassium channel subunits and synapse-associated protein 90 to septate-like junctions in rat cerebellar Pinceaux. Mol Brain Res 42:51-61.

Lo W, Molloy R, Hughes TE (1998) Ionotropic glutamate receptors in the retina: moving from molecules to circuits. Vision Res 38:1399-1410.

Lue RA, Marfatia SM, Branton D, Chishti AH (1994) Cloning and characterization of hdlg: the human homologue of the Drosophila discs-large tumor suppressor binds to protein 4.1. Proc Natl Acad Sci USA 91:9818-9822.

Mammen AL, Huganir RL, O'Brien RJ (1997) Redistribution and stabilization of cell surface glutamate receptors during synapse formation. J Neurosci 17:7351-7358.

Massey SC (1990) Cell types using glutamate as a neurotransmitter in the vertebrate retina. In: Progress in retinal research (Osborne N, Chader G, eds), pp 399-426. Oxford: Pergamon.

Massey SC, Redburn DA (1987) Transmitter circuits in the vertebrate retina. Prog Neurobiol 28:55-96.

Morgans CW, El Far O, Berntson A, Wässle H, Taylor WR (1998) Calcium extrusion from mammalian photoreceptor terminals. J Neurosci 18:2467-2474.

Müller B, Peichl L (1989) Topography of cones and rods in the tree shrew retina. J Comp Neurol 282:581-594.

Müller BM, Kistner U, Veh RW, Cases-Langhoff C, Becker B, Gundelfinger ED, Garner CC (1995) Molecular characterization and spatial distribution of SAP97, a novel presynaptic protein homologous to SAP90 and the Drosophila discs-large tumor suppressor protein. J Neurosci 15:2354-2366.

Müller BM, Kistner U, Kindler S, Chung WJ, Kuhlendahl S, Lau L-F, Veh RW, Huganir RL, Gundelfinger ED, Garner CC (1996) SAP 102, a novel postsynaptic protein that interacts with the cytoplasmic tail of the NMDA receptor subunit NR2B. Neuron 17:255-265.

Niethammer M, Kim E, Sheng M (1996) Interaction between the C terminus of NMDA receptor subunits and multiple members of the PSD-95 family of membrane-associated guanylate kinases. J Neurosci 16:2157-2163.
Piccolino M (1995) Cross-talk between cones and horizontal cells through the feedback circuit. In: Neurobiology and clinical aspects of the outer retina (Djamgoz MBA, Archer SN, Vallerga S, eds), pp 221-248. London: Chapman and Hall.

Rao A, Craig AM (1997) Activity regulates the synaptic localization of the NMDA receptor in hippocampal neurons. Neuron 19:801-812.

Sagar SM (1986) NADPH diaphorase histochemistry in the rabbit retina. Brain Res 373:153-158.

Sassoè-Pognetto M, Wässle H (1997) Synaptogenesis in the rat retina: subcellular localization of glycine receptors, $\mathrm{GABA}_{\mathrm{A}}$ receptors, and the anchoring protein gephyrin. J Comp Neurol 381:158-174.

Sassoè-Pognetto M, Wässle H, Grünert U (1994) Glycinergic synapses in the rod pathway of the rat retina: cone bipolar cells express the $\alpha 1$ subunit of the glycine receptor. J Neurosci 14:5131-5146.

Sheng M (1996) PDZs and receptor/channel clustering: rounding up the latest suspects. Neuron 17:575-578.

Szél A, Röhlich P, Caffé AR, van Veen T (1996) Distribution of cone photoreceptors in the mammalian retina. Microsc Res Tech 35:445-462.

Wässle H, Koulen P, Brandstätter JH, Fletcher EL, Becker C-M (1998) Glycine and GABA receptors in the mammalian retina. Vision Res 38:1411-1430.

Watanabe M, Mishina M, Inoue Y (1994) Differential distributions of the NMDA receptor channel subunit mRNAs in the mouse retina. Brain Res 634:328-332.

Wenzel A, Scheurer L, Künzi R, Fritschy JM, Möhler H, Benke D (1995) Distribution of NMDA receptor subunit proteins NR2A, 2B, 2C, and 2D in rat brain. NeuroReport 7:45-48.

Wenzel A, Benke D, Möhler H, Fritschy J-M (1997a) N-methyl-Daspartate receptors containing the NR2D subunit in the retina are selectively expressed in rod bipolar cells. Neuroscience 78:1105-1112.

Wenzel A, Fritschy JM, Möhler H, Benke D (1997b) NMDA receptor heterogeneity during postnatal development of the rat brain: differential expression of the NR2A, NR2B, and NR2C subunit proteins. J Neurochem 68:469-478.

Wong-Riley MTT, Huang Z, Liebl W, Nie F, Xu H, Zhang C (1998) Neurochemical organization of the macaque retina: effect of TTX on levels and gene expression of cytochrome oxidase and nitric oxide synthase and on the immunoreactivity of $\mathrm{Na}^{+} \mathrm{K}^{+}$ATPase and NMDA receptor subunit I. Vision Res 38:1455-1477.

Yazulla S (1995) Neurotransmitter release from horizontal cells. In: Neurobiology and clinical aspects of the outer retina (Djamgoz MBA, Archer SN, Vallerga S, eds), pp 249-271. London: Chapman and Hall. 